\title{
O DIREITO À PREGUIÇA: UMA ANÁLISE DO TEMPO DE TRABALHO $X$ TEMPO LIVRE
}

The right to laziness: an analysis of the time of work $x$ free time

\author{
Camila Lopes Ferreira \\ Luiz Alberto Pilatti \\ Antonio Carlos Frasson
}

\begin{abstract}
Resumo
O presente artigo tem como objetivo discutir a relação sobre o tempo de trabalho e o tempo de não-trabalho, com o intuito de refletir sobre essa situação, avaliando seus prós e contras, envolvendo empregados e empregadores. Para isso, foram utilizadas diferentes análises, entre as quais o manifesto "O direito à preguiça" de Paul Lafargue datado de 1883 que reivindicava direitos dos operários como redução da jornada de trabalho, direito a uma vida alheia ao trabalho, entre outras. Vale lembrar que o lazer, por exemplo, uma das atividades que devem fazer parte do tempo de nãotrabalho, tem impacto direto na qualidade de vida das pessoas, o que é fundamental até mesmo para $\circ$ melhor desempenho nas atividades profissionais.
\end{abstract}

Palavras-chave: Tempo; Trabalho; Preguiça.

\begin{abstract}
The present article discusses the relationship between work time and non-work time, with the aim of reflecting on this situation and evaluating its pros and cons, as regards employees and employers. Different analyses were used to achieve this, including the manifesto, "The Right to Laziness," by Paul Lafargue, dated of 1883. It demanded the rights of laborers, such as a reduction in work hours, and the right to enjoy one's life outside the workplace, among others. It's important to mention that leisure time, for example - an activity that must be part of one's non-work time - directly impacts a person's quality of life, and
\end{abstract}


is fundamental to performing one's professional activities better.

Keywords: Time; Work; Laziness.

\section{Introdução}

Em função da busca contínua pela sobrevivência em um mercado cada vez mais competitivo, as organizações estão tendo que se adaptar a esta realidade. Antes, para se tomar decisões, podia-se confiar, até mesmo, na intuição. Hoje, não apenas. Precisa-se estar atento, também, a uma realidade que deve estar integrada a clientes, fornecedores, acionistas e colaboradores.

Visando o aumento da produtividade para a efetiva conquista de mercado, as organizações estão se preocupando com os seus colaboradores. Essa preocupação não é de hoje (embora, maior atualmente); muito pelo contrário, vem de tempos atrás.

Para Carmo (1998, p. 136), "Essas mudanças estão trazendo enormes transformações no campo do trabalho. Antes, o adestramento era suficiente para os trabalhadores fazerem a mesma coisa durante toda a sua vida".

O manifesto escrito por Paul Lafargue em 1.883, "O direito à preguiça", tem como tema "[...] o elogio à preguiça, como condição para o desenvolvimento físico, psíquico e político do proletariado" (CHAUI, 1999, p. 33).

Muitas pessoas acreditavam que com o passar do tempo, com as novas tecnologias que estavam por surgir, poder-se-ia trabalhar menos e aproveitar mais a vida.

$\mathrm{Na}$ teoria, tudo que acontece vem para facilitar as atividades seja através da globalização, da robotização; e, até mesmo, de inúmeros programas implantados nas organizações, visando sempre o aumento da produtividade.

Na prática, a realidade é diferente. As pessoas vivem em função do trabalho. Precisam trabalhar não só para suprir suas necessidades básicas, mas para terem condições de sobreviver e, até mesmo, para não serem excluídas da sociedade taxativa na qual se vive atualmente.

Neste contexto, todos os estudos relacionados ao mundo do trabalho, são de relevante importância, encontrando-se aí o objetivo desta reflexão, a 
qual será uma revisão de literatura sobre o mundo do trabalho e os seus direitos.

\section{0 mundo do trabalho e o direito à preguiça}

Trabalho é a "[...] aplicação das forças e faculdades humanas para alcançar um determinado fim: $O$ trabalho permite ao homem certo domínio sobre a natureza; divide bem o tempo entre o trabalho e o lazer" (FERREIRA, 1986, p. 1695).

Já para Silva (2005, p. 148), "Entende-se por trabalho, uma atividade real executada por uma pessoa incluindo o seu conhecimento e suas relações pessoais".

\footnotetext{
[...] a própria palavra trabalhar deriva do latim tripaliare, que significa torturar por meio de tripalium (instrumento formado por três paus, próprio para atar os condenados ou para manter presos os animais difíceis de ferrar). Igualmente, a palavra labor é sinônimo de trabalho, mas também lembra sofrimento, dor, fadiga. Se admitirmos que a vida humana depende do trabalho, $e$ este causa tanto desprazer, só podemos concluir, por enquanto, pela inevitável infelicidade humana. (ARANHA, 1997, p. 21).
}

Segundo Oliveira (2004, p. 26), "Trabalhar, então, tem o significado de garantir as condições objetivas e subjetivas para a manutenção e o desenvolvimento da existência do homem, o que só poderia trazer satisfação e prazer".

O trabalho deveria ser fonte de satisfação e prazer. Na teoria, sim; mas, e na prática? Quantas pessoas sentem prazer no trabalho que realizam? É preciso compreender o mundo do trabalho e para Almeida (2005, p. 82):

\footnotetext{
Sairão na frente, na ampliação de novos serviços que promovam qualidade de vida, aqueles que não somente têm o entendimento do mundo do trabalho, mas aqueles que conheçam o mundo da vida, das relações, das artes, da cultura, onde os seres se sensibilizam, onde a vida pulsa.
}

As pessoas se submetem ao trabalho em função das suas necessidades fisiológicas ou de segurança; e, este, é percebido como uma obrigação que traz cansaço e sofrimento. Fazem o que precisam fazer sem mesmo nem 
saber o que estão fazendo, simplesmente para cumprir com as suas obrigações.

Chaui (1999, p. 33) encontra "[...] o significado do trabalho no modo de produção capitalista, isto é, a divisão social do trabalho e a luta de classes". $\mathrm{Na}$ realidade, para esta autora, os empregados sucumbem-se aos empregadores devido às suas necessidades, fazendo com que estes tenham tempo para o lazer, para o ócio e para uma melhor qualidade de vida.

Para Marx (1987, p. 41):

\footnotetext{
Que mesmo a mais favorável das situações para a classe operária, mesmo o mais rápido dos aumentos do capital que traga à vida material do operário um pouco de melhoria, não suprime o antagonismo entre os seus interesses e os interesses do burguês, os interesses do capitalista. Lucro e salário estão, exatamente como antes, na razão inversa um do outro.
}

Lafargue (1999, p. 79) diz: "Trabalhem, trabalhem, proletários, para aumentar a riqueza social e suas misérias individuais, trabalhem, trabalhem para que, ficando mais pobres, tenham mais razões para trabalhar e tornarem-se miseráveis". Lafargue denomina isto de lei inexorável da produção capitalista, não considerando a culpa da divisão de classes somente dos burgueses, mas de todos. Afinal de contas os trabalhadores se sujeitam a essa situação.

"Desde as mais antigas civilizações existe divisão entre aqueles que mandam - e portanto pensam, concebem, inventam - e os que só obedecem e executam" (ARANHA, 1997, p. 26). Sempre esteve presente a divisão de classes sociais, seja entre a burguesia e o proletariado, os senhores feudais e os escravos, até os empregadores e os empregados.

As condições sofreram grandes alterações no decorrer dos anos. Analisando os tempos mais remotos, "[...] as condições reais eram brutais e dolorosas. As pessoas trabalhavam da madrugada até o anoitecer sob condições intoleráveis de doença, sujeira, perigo e escassez de recursos." (DAVIS, 1992, p. 6).

$\mathrm{Na}$ verdade, os trabalhadores precisam trabalhar dessa forma por uma questão de sobrevivência. Marx (1987, p. 41) afirma:

Dizer que o operário tem interesse no crescimento do capital significa apenas isto: quanto mais rapidamente o operário faz 
Marx defende a idéia da submissão do empregado ao empregador; e, Chaves (2007, p. 98) complementa dizendo que o empregador também é sucumbido, não à outra pessoa, mas ao próprio capital:

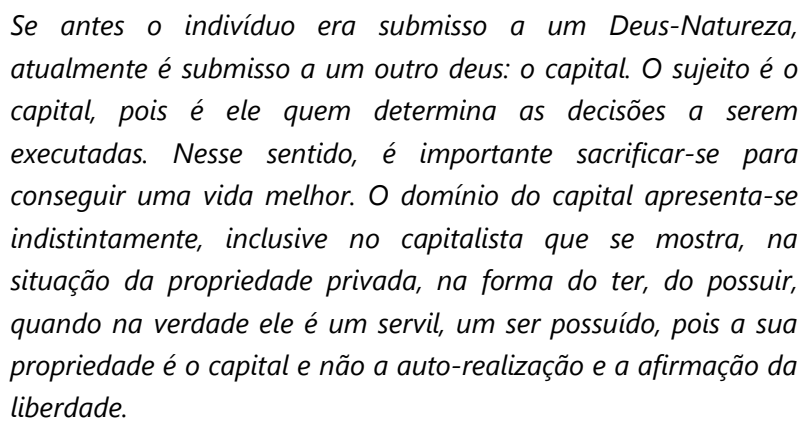

"Na década de 30, diz Rifkin, os trabalhadores organizados começaram a reivindicar redução da jornada de trabalho como saída justa para a crise" (CARMO, 1998, p. 66).

Com a regulamentação da jornada de trabalho, o empregado deixou de trabalhar 15, 16 e até 17 horas por dia; mas, continua passando a maior parte de seu tempo dentro de uma organização, vivendo em função desta, a qual impõe regras que devem ser seguidas à risca para que se tenha condições de manter a empregabilidade.

Mesmo sendo o trabalho tão desgastante, havia "[...] um interesse mútuo entre os empregados, que trabalhavam mais para conseguir mais dinheiro, e os proprietários, que se beneficiavam com o lucro obtido pela maior produção" (MEGGINSON, MOSLEY e PIETRI, 1998, p. 40).

Marx e Engels (1990, p. 102) já diziam em 1876: "É preciso uma modificação completa de todo o nosso modo de produção passado, e com ele, de todo o nosso regime social actual".

Mesmo com as mudanças ocorridas nesse mais de um século, o manifesto de Lafargue continua válido. Transformações aconteceram, a realidade mudou e ao mesmo tempo ainda se vive praticamente da mesma forma. 
Hoje, criou-se, para Antunes (2000, p. 170):

"[...] uma classe trabalhadora mais heterogênea, mais fragmentada e mais complexificada, dividida entre trabalhadores qualificados e desqualificados, do mercado formal e informal, jovens e velhos, homens e mulheres, estáveis e precários, imigrantes e nacionais, etc [...]".

Para Kanaane e Ortigoso (2001, p. 85), "É preciso capacitar as pessoas para uma atuação eficaz com foco no futuro", necessitando estas estarem preparadas para um mercado cada vez mais exigente, mutante e competitivo.

O que as empresas realmente querem é produtividade. "Numa sociedade de mercado, o empregado eficiente deve ser um ator despersonalizado. Espera-se dele que acate as determinações impostas, de cima para baixo, e que definem o papel que tem que desempenhar" (RAMOS, 1989, p. 98).

O mercado de trabalho exige cada vez mais dos trabalhadores, até mesmo em seu tempo livre, estes precisam muitas vezes estar estudando e se preparando para que tenham condições de obter resultados compatíveis com os seus desejos.

A realidade hoje é outra, as exigências são cada vez maiores. Para Pilatti (2007, p. 48), "A diversidade desejada pelo setor produtivo apresenta uma conotação perversa: deixou de se valorizar o igual. A individualidade, com capacidade elevada de trabalho em equipe, não é mais apenas desejada, é requerida."

Segundo Moscovici (2001, p. 13):

\footnotetext{
Todas as soluções milagrosas fracassaram, e irão fracassando, na medida em que não se descobrir o verdadeiro lugar que merece $o$ agente de tantas transformações e também dos desequilíbrios. $O$ capitalismo, tal como se apresenta hoje, não consegue mais se impor como projeto de solução para os problemas que afligem a humanidade. Também já faleceu o socialismo em experiências mais radicais. Por quê? Simplesmente porque não respeitaram o ser humano.
}

"Hoje, como ontem, os trabalhadores ainda precisam lutar pelo direito à preguiça, sobretudo se considerarmos, ao lado do Estado de Bem-Estar [...]" 
(CHAUI, 1999, p. 49).

Essa necessidade existiu e perpetua até hoje. "O tema preguiça já é conhecido por nós. De tão comentado ele já se incorporou ao imaginário popular. Apesar disso, poucos se autodenominam preguiçosos. Os outros é que o são" (CARMO, 1998, p. 7).

Para Lafargue (1999, p. 112), a classe operária deveria lutar não para exigir os Direitos do Homem ou o Direito ao Trabalho, mas reivindicar um trabalho digno não mais de três horas diárias. Esse autor ainda diz: "Preguiça, tenha piedade de nossa longa miséria! Preguiça, mãe das artes e das virtudes nobres, seja o bálsamo das angústias humanas!"

A preguiça é conotada como um pecado capital, mas até que ponto isso é correto? Sob a ótica de Lafargue, a preguiça é um direito de todo trabalhador.

Em se tratando de Brasil, ainda segundo Carmo (1998, p. 7), atribui-se "[...] tanto o atraso econômico do país quanto seus desmandos à tendência para a preguiça ou deixar tudo para o dia seguinte. Seria a preguiça uma forma de rebeldia diante da exploração?" É difícil dizer. As pessoas acabam tão sucumbidas ao trabalho que aquele que não está trabalhando não é bem visto pela sociedade.

A sociedade hoje faz com que as pessoas trabalhem cada vez mais, para conseguirem melhores salários, melhores posições, simplesmente pelo fato de que quanto mais se tem, mais se quer. Se já era difícil convencer os operários épocas passadas de como era triste a sua realidade, hoje, então, nesse mundo consumista, é praticamente impossível.

Dizia Lafargue (1999, p. 84):

Mas convencer o proletariado de que a palavra que thes inocularam na mente é perversa, de que o trabalho desenfreado a que se entregou desde o começo do século é o mais terrivel flagelo que assola a humanidade, de que o trabalho só se tornará um condimento do prazer da preguiça, um exercício benéfico para o organismo humano, uma paixão útil ao organismo social, quando for sabiamente regulamentado e limitado a um máximo de três horas por dia - isso é uma tarefa árdua e acima de minhas forças.

Isso será possível um dia? Para Moscovici (2001, p. 15): 
trabalho exige que trabalho e qualidade de vida estejam de mãos dadas. Estar ocioso hoje não é mais sinônimo de estar feliz. Nenhum ser humano pode se considerar feliz sem alguma realização. O trabalho the permite aflorar um enxame de qualidades e valores interiores, e, a partir deles, podem ser criadas melhores oportunidades de participação.

Num estudo sobre o mundo do trabalho, Assis (1999, p. 123) comenta a respeito do futuro:

As pessoas trabalharão em projetos com começo, meio e fim. Terminado um projeto, elas passarão para outro, na mesma empresa ou em outra, ou até mesmo em casa. Poderão desenvolver esses projetos em regime de tempo parcial, de trabalho temporário ou de trabalho a distância. Nesse sentido, o trabalho será feito com muito mais liberdade.

Será mesmo? O trabalho faz parte da vida das pessoas economicamente ativas; onde a maioria, mesmo sem querer, acaba vivendo em função deste. Para Marx e Engels (1990, p. 87):

O trabalho, dizem os economistas, é a fonte de todas as riquezas. É-o, efectivamente... em conjunto com a natureza, que thes fornece a matéria que ele transforma em riqueza. Mas o trabalho é muito mais do que isso. É a condição primeira fundamental de toda a vida humana, e é-o ao ponto de, num certo sentido, nos levar a dizer: o trabalho criou o próprio homem.

Mesmo trabalhando com esta afirmação de Marx e Engels, o trabalho foi visto por muitas pessoas como algo ruim, como uma obrigação a ser cumprida desde os tempos mais remotos.

A divisão de classes torna real a veracidade desta colocação. Uns têm demais; outros, de menos. Nem todos os trabalhos são considerados dignos e recebem a sua devida importância. Muitas vezes o reconhecimento de determinada atividade vem pelo status que a mesma proporciona ao trabalhador e não à efetividade realizada por ele.

\section{O lazer como tempo de não trabalho}


Qualidade de vida: todos merecem tê-la Realização profissional: todos conseguem alcançá-la? Stress: todos conseguem vencê-lo? Estas são algumas conseqüências do trabalho que influenciam as pessoas.

Existem muitos estudos a respeito do trabalho e suas conseqüências no lado pessoal da vida dos trabalhadores. Qual será o real impacto? O correto seria encontrar o equilíbrio pessoal e profissional, o equilíbrio entre o tempo do trabalho e o tempo do não trabalho.

O ideal seria ter uma atividade profissional que fosse capaz de suprir as suas necessidades básicas e ainda sobrasse tempo e dinheiro para outras realizações, como o lazer, por exemplo.

Para Pilatti (2007, p. 41), "O tempo de não-trabalho, a despeito dos impressionantes avanços tecnológicos, está sendo diminuído para os trabalhadores. Os limites do trabalho mudaram".

Na concepção de Elias (1992, p. 108-110), o tempo pode ser dividido em tempo de trabalho e tempo livre. As atividades de tempo livre podem ser divididas em cinco esferas, assim distribuídas:

a) trabalho privado e administração familiar: nesse contexto estão englobadas todas as atividades da família, como provisão da casa, orientação dos filhos, estratégia familiar, entre outras;

b) repouso: a esta categoria pertence o não fazer nada, as futilidades e, acima de tudo, o dormir;

c) provimento das necessidades biológicas: aqui se encontram atividades como comer, beber, defecar, fazer amor, enfim suprir as necessidades básicas;

d) sociabilidade: não é considerada trabalho, embora possa auxiliar neste, através de relacionamentos com colegas de trabalho ou superiores hierárquicos; e, também, atividades que não têm nenhuma relação trabalhista, como ir a um bar, a uma festa, a um clube;

e) categoria das atividades miméticas ou jogo: aqui se encontram as atividades de lazer, tais como a ida ao teatro, ao cinema, à pesca, à caça, dançar, ver televisão.

Todo ser humano tem direito à esse tempo livre. "Esse tempo livre é tão importante para o trabalhador quanto o tempo dedicado à produção. Nesse tempo ele elabora o cotidiano do trabalho à distância, permitindo-lhe criticá-lo ou mesmo valorizar seus aspectos centrais" (BAVA JR, 2000, p. 71).

Não se pode viver só em função do trabalho e para o trabalho. É claro que isto acontece com aquelas pessoas que ainda possuem um emprego. $\mathrm{E}$ 
aquelas que perderam seu cargo para uma máquina ou simplesmente não conseguem colocação neste mercado tão competitivo? E não são poucas. Em função do desemprego quantas pessoas têm tempo livre e não podem utilizá-lo para atividades de lazer? Sem trabalho não se tem dinheiro e, sem dinheiro, não se tem lazer.

Para Gutierrez (2001, p. 6):

O lazer, como instância distinta e específica da vida social, só é percebido com o advento da Revolução Industrial e a separação dos espaços familiares, comunitários e profissionais, ou seja, existe no objeto lazer um aspecto histórico de 'não-trabalho'.

O que existe é uma divergência entre trabalho e lazer em função das desigualdades sociais, da má distribuição de renda, entre outros fatores. Isso faz com que alguns tenham tempo e dinheiro para gastar com lazer, assim como muitos não tenham nem para suprir as necessidades básicas.

Nessa relação fica difícil se definir o tempo que deve ser destinado ao lazer. $\mathrm{O}$ que se precisa ter em mente é que assim como o trabalho é fundamental o lazer também o é. Talvez como uma necessidade menor mas não indispensável a sobrevivência humana. São poucos os trabalhadores que conseguem usufruir do lazer merecido. Para muitos, pertencentes a essa sociedade capitalista, lazer é tempo ocioso. E como tempo é dinheiro, não se deve desperdiçá-lo.

A crise trabalho e lazer teve um crescimento com a sociedade capitalista, onde o trabalho passou a ocupar posição de destaque enquanto o lazer deixou de fazer parte pois não se tinha tempo suficiente. $\mathrm{Na}$ realidade, "Na sociedade de mercado, a noção de lazer tem sido degradada, porque se tornou sinônimo de ociosidade, passatempo, diversão conotações que o lazer nunca teve antes" (RAMOS, 1989, p. 130).

Quando não estava trabalhando em suas jornadas de 16 horas diárias, o operário tinha que comer, dormir e descansar, ou seja, preparar-se para voltar a trabalhar. Isso tornou os operários alienados ao seu trabalho. "O tempo livre como o tempo do trabalho são medidas da existência do indivíduo em sociedade [...]" (BAVA JR, 2000, p. 72).

Para finalizar, Moscovici (2001, p. 134) diz: "Não obstante a conjugação de variados fatores, a própria pessoa é a maior responsável pela construção 
da qualidade de sua vida. Cuidar da saúde, alimentação, exercícios físicos, repouso, lazer são atribuições indelegáveis de cada um".

\section{Considerações Finais}

Tudo mudou. O desenvolvimento industrial trouxe nada mais do que trabalhadores bitolados em suas práticas profissionais, inseridos numa busca incansável pelo ter cada vez mais, deixando o lado prazeroso da vida de lado.

O problema é que as pessoas não conseguem identificar o tempo do não-trabalho como uma necessidade importante para o seu crescimento e melhoria da sua qualidade de vida. O que fica parecendo é que só as pessoas que têm uma situação financeira melhor é que têm direito ao lazer, é que têm direito ao ócio.

Até mesmo porque essas também não estão dando à devida importância ao tempo de não-trabalho. Dominadores e dominados continuam existindo. Muitas empresas, hoje, acabam rotulando seus trabalhadores como "colaboradores".

Mais uma vez na teoria tudo pode ser dito. Mas, e na prática, esse discurso tem validade? Não se deve viver em função do trabalho, independente do nível administrativo que esteja inserido. É fundamental dar valor ao tempo livre.

O objeto desse estudo é a reflexão sobre o tempo de trabalho e o tempo de não-trabalho e o direito à preguiça, não só na luta pela melhor qualidade de vida dos empregados; mas, também, dos empregadores.

Viver em função do trabalho é uma realidade que permeia a vida de todos os trabalhadores, onde o lazer e trabalho deveriam andar juntos. Esse é um desafio a ser superado.

O que precisa ser feito é se repensar a respeito do assunto, dos valores muitas vezes impostos por essa sociedade capitalista e avaliar até que ponto tudo vale a pena. As pessoas deveriam ser educadas para ter o lazer como entendimento básico para a sua sobrevivência e para sua melhor qualidade de vida.

Quando se podia imaginar que manifestações elaboradas há séculos permanecessem até os dias de hoje válidas?

E o que é mais triste, é que as pessoas assistem a essas transformações 
caladas, submissas ao mundo capitalista no qual se vive, sem se dar conta de que a vida depende única e exclusivamente de cada um.

\section{Referências}

ALMEIDA, M. A. B. de. Empresa e qualidade de vida novos rumos e desafios. In: GONÇALVES, A.; GUTIERREZ, G. L.; VILARTA, R. (Org.). Gestão da Qualidade de vida na empresa. Campinas: IPES Editorial, 2005.

ANTUNES, R. Adeus ao trabalho: ensaio sobre as metamorfoses e a centralidade do mundo do trabalho. São Paulo: Cortez, 2000.

ARANHA, M. L. de A. Trabalhar pra quê? In: KUPSTAS, M. (Org.). Trabalho em debate. São Paulo: Moderna, 1997.

ASSIS, M. de. 0 mundo do trabalho. 2. ed. Brasília: SENAI, 1999.

BAVA JR, A. C. A sociologia do trabalho. São Paulo: Afiliada, 2000.

CARMO, P. S. do. 0 trabalho na economia global. São Paulo: Moderna, 1998.

CARMO, P. S. do. História e ética do trabalho no Brasil. São Paulo: Moderna, 1998.

CHAUI, M. In: LAFARGUE, P. O direito à preguiça. São Paulo: Hucitec; Unesp, 1999.

CHAVES, J. de C. A liberdade e a felicidade do indivíduo na racionalidade do trabalho no capitalismo tardio: a (im)possibilidade administrada. Tese (Doutorado em Psicologia Social) - Pontifícia Universidade Católica de São Paulo, São Paulo, 2007.

DAVIS, K. Comportamento humano no trabalho. São Paulo: Pioneira, 1992.

ELIAS, N. A busca da excitação. Lisboa: Difel, 1992. 
FERREIRA, A. B. de H. Novo dicionário Aurélio da língua portuguesa. Rio de Janeiro: Nova Fronteira, 1986.

GUTIERREZ, G. L. Lazer e prazer: questões metodológicas e alternativas políticas. Campinas: Autores Associados, 2001.

KANAANE, R.; ORTIGOSO, S. A. F. Manual de treinamento e desenvolvimento do potencial humano. São Paulo: Atlas, 2001.

LAFARGUE, P. O direito à preguiça. São Paulo: Hucitec; Unesp, 1999.

MARX. K. Trabalho assalariado e capital. 4. ed. São Paulo: Global, 1987.

MARX, K.; ENGELS, F. Princípios do comunismo e outros textos. São Paulo: Mandacaru, 1990.

MEGGINSON, L. C.; MOSLEY. D. C.; PIETRI, P. H. Administração: conceitos e aplicações. 4. ed. São Paulo: Harbra, 1998.

MOSCOVICI, F. A organização por trás do espelho. Rio de Janeiro: José Olympio, 2001.

OLIVEIRA, C. B. de. Sobre lazer, tempo e trabalho na sociedade de consumo. Conexões, v. 2, n. 1, 2004.

PILATTI, L. A. Qualidade de vida e trabalho: perspectivas na sociedade do conhecimento. In: VILARTA, R.; GUTIERREZ, G. L.; CARVALHO, T. H. P. F. de.; GONÇALVES, A. (Org.). Qualidade de vida e novas tecnologias. Campinas: IPES Editorial, 2007.

RAMOS, A. G. A nova ciência das organizações: uma reconceituação da riqueza das nações. Rio de Janeiro: Fundação Getúlio Vargas, 1989.

SILVA, T. T. R. da. Pensando a gestão estratégica, saúde e a qualidade de vida. In: GONÇALVES, A.; GUTIERREZ, G. L.; VILARTA, R. (Org.). Gestão da Qualidade de vida na empresa. Campinas: IPES Editorial, 2005. 